\title{
PROGNOSTIC ROLE OF THE EXPRESSION OF INVASION- RELATED MOLECULES IN GLIOBLASTOMA
}

\begin{tabular}{|c|c|}
\hline Journal: & $J N L S-A$ \\
\hline Manuscript ID & CEN-2015-12-OA-1599.R1 \\
\hline Manuscript Type: & Original Article \\
\hline Date Submitted by the Author: & 21-Mar-2016 \\
\hline Complete List of Authors: & $\begin{array}{l}\text { Virga, József; University of Debrecen, Department of Neurosurgery } \\
\text { Bognár, László; University of Debrecen, Department of Neurosurgery } \\
\text { Hortobágyi, Tibor; University of Debrecen, Department of Neuro-Pathology } \\
\text { Zahuczky, Gábor; University of Debrecen, Centre for Clinical Genomics and } \\
\text { Personalized Medicine } \\
\text { Csősz, Éva; University of Debrecen, Research Centre for Molecular } \\
\text { Medicine } \\
\text { Kalló, Gergő; University of Debrecen, Research Centre for Molecular } \\
\text { Medicine } \\
\text { Toth, Judit; University of Debrecen, Oncology } \\
\text { Hutóczki, Gábor; University of Debrecen, Department of Neurosurgery } \\
\text { Reményi-Puskár, Judit; University of Debrecen, Department of } \\
\text { Neurosurgery } \\
\text { Steiner, László; University of Debrecen, Centre for Clinical Genomics and } \\
\text { Personalized Medicine } \\
\text { Klekner, Álmos; University of Debrecen, Department of Neurosurgery }\end{array}$ \\
\hline Keywords (in English): & expression, extracellular matrix, glioblastoma, survival, prognosis \\
\hline Abstract: & $\begin{array}{l}\text { BACKGROUND } \\
\text { Glioblastoma multiforme (GBM) is the most common malignant disease of } \\
\text { the central nervous system. Its prognosis is rather unfavorable, and the } \\
\text { median overall survival of patients is } 16-24 \text { months. The main cause of the } \\
\text { poor survival data is the extensive invasion of cancer cells to the } \\
\text { neighboring parenchyma, thus leading to inevitable local recurrence. The } \\
\text { extracellular matrix (ECM) is a known factor in tumor invasion, and } \\
\text { differences in the ECM of non-tumor brain and glioblastoma has been } \\
\text { proved. } \\
\text { METHODS } \\
\text { In this research, } 20 \text { invasion-related expressions of ECM components were } \\
\text { determined in } 26 \text { GBM flash-frozen samples using quantitative reverse } \\
\text { transcription-polymerase chain reaction and proteomic measurements. } \\
\text { Expression data were then set against the survival data of the patients. } \\
\text { RESULTS } \\
\text { Significant alterations between groups with different survival rates could } \\
\text { not be established in the individual evaluation of the expression level of the }\end{array}$ \\
\hline
\end{tabular}


selected molecules. However, statistical analysis of the expression pattern of invasion-related molecules revealed correlation with prognosis. The positive predictive values of the mRNA and the proteomic expression studies were 0.85 and 0.89 , respectively. The receiver operation characteristic value was 0.775 for the mRNA expression data and 0.875 for the protein expression data. Furthermore, a group of molecules, including brevican, cadherin-12, integrin $\beta 1$, integrina3, laminin $a 4$, and laminin $\beta 1$, playing a prominent role in invasion was identified.

\section{CONLCUSIONS}

Joint assessment of the expression of invasion-related molecules provides a specific invasion spectrum of the tumor that correlates with the survival of glioblastoma patients. Using statistical classifiers enables the adoption of an invasion spectrum as a considerably accurate prognostic factor while gaining predictive information on potential molecular oncotherapeutic targets at the same time. 


\section{PROGNOSTIC ROLE OF THE EXPRESSION OF INVASION-RELATED MOLECULES IN GLIOBLASTOMA}

József Virga, M.D. ${ }^{a} \#$, László Bognár, M.D., PhDª, Tibor Hortobágyi M.D, $\mathrm{PhD}^{\mathrm{b}}$, Gábor Zahuczky M.Sc., $\mathrm{PhD}^{\mathrm{c}}$, Éva Csősz M.Sc., PhD ${ }^{\mathrm{d}}$, Gergő Kalló M.Sc. ${ }^{\mathrm{d}}$, Judit Tóth M.D ${ }^{\mathrm{e}}$, Gábor Hutóczki M.Sc., PhD ${ }^{a}$, Judit Reményi-Puskár M. Sc. ${ }^{a}$, László Steiner M.Sc. ${ }^{c}$, Almos Klekner M.D. $\mathrm{PhD}^{\mathrm{a}}$

\#These authors contributed equally

a - University of Debrecen Clinical Center - Department of Neurosurgery, Debrecen, Hungary, 4032, Nagyerdei krt. 98.

b - University of Debrecen Clinical Center - Department of Pathology, Debrecen, Hungary, 4032, Nagyerdei krt. 98.

c - University of Debrecen Clinical Center - Centre for Clinical Genomics and Personalized Medicine, Debrecen, Hungary, 4032, Nagyerdei krt. 98.

d - University of Debrecen Clinical Center Research - Research Centre for Molecular Medicine, Debrecen, Hungary, 4032, Nagyerdei krt. 98.

e - University of Debrecen Clinical Center - Department of Oncology, Debrecen, Hungary, 4032, Nagyerdei krt. 98.

\section{Corresponding author:}

Almos Klekner, M.D., PhD

University of Debrecen Clinical Center - Department of Neurosurgery

Debrecen, Hungary, 4032, Nagyerdei krt. 98.

Email: neurosurgery.debrecen@freemail.hu, Tel.: +3620-973-6080 Fax: +36-52-419-418

Conflict of interest: The authors declare that they have no conflict of interest. 
Virga et al.

\section{INTRODUCTION}

Glioblastoma multiforme (GBM) is the most common tumor of the central nervous system (CNS), accounting for nearly half of CNS malignancies, and the incidence rate of GBM is 2$3 / 100,000^{1}$. The prognosis of the disease, despite accurate therapy, is rather unfavorable because of the almost inevitable local recurrence ${ }^{2,3}$. The mean overall survival (OS) of adequately treated patients is between 16 and 24 months. 3,4

Treating GBM patients demands the cooperation of a neurosurgeon, a radiotherapist and an oncologist, as GBM requires a complex neuro-oncologic approach. However, complete surgical removal is hindered by the invasion of tumor cells, which show only partial sensitivity to stand-alone irradiation and traditional chemotherapeutic agents ${ }^{2,5,6}$. According to the protocols used today, patients undergo biopsy or mass-reducing surgery and then concurring chemo-irradiation, followed by temozolomide monotherapy as long as the physical condition of the patient allows or until the disease progresses ${ }^{2,4,6,7}$. After progression, treatment can be complemented with a biological treatment (bevacizumab, which is an anti-VEGF monoclonal antibody). However, no major advances in the oncotherapy of GBM have been made since temozolomide was introduced ${ }^{6,8}$.

Previous research has proved that extracellular matrix (ECM) significantly affects the clinical behavior of tumors ${ }^{9,10}$. The amount of ECM in tumor tissue is greater than that in normal brain tissue (50\% vs. $20 \%$ ), and the composition of tumor ECM differs from that of nontumor $\mathrm{ECM}^{11-15}$. The changed composition of ECM, with some components expressing in a higher or lower amount and some being undetectable in normal brain but suddenly appearing in ECM, seems to correlate with the invasivity of $\mathrm{GBM}^{13,15-17}$. Understanding the ECM composition of normal and tumorous brain is not only academically relevant, but it also 
Virga et al.

provides important information to clinicians so that they are able to correctly choose the right targets of molecular therapy for their patients.

In today's clinical practice, only a single protocol is available for the neuro-oncological treatment of patients with GBM, and the efficacy of this protocol shows a great difference among patients. ${ }^{1,2,4,18-21}$. No predictive factors are available in routine clinical practice to assess the treatment options of GBM patients, although screening patients with poor prognosis may give an opportunity to use other anti-cancer agents instead of the drugs of the current treatment protocol. As the inefficacy of oncotherapy lies in the peritumoral invasion of cancer cells that lead to local recurrence, studying the expression of invasionrelated ECM molecules and correlating the obtained data with patients' survival can produce essential information on patient outcome. Furthermore, during the expression analysis, new targets are likely to be identified for research groups focusing on the anti-invasive therapy of GBM, which is a recently revived field of neuroscience.

This study aims to investigate the prognostic role of the expression levels of invasion-related ECM molecules using samples from GBM patients. Furthermore, the composition of ECM in groups with different survival rates is analyzed to identify the key molecules in the development of the invasive character of glioblastoma.

\section{PATIENTS AND METHODS}

Intraoperatively harvested, flash frozen GBM tissue samples taken from the Brain Tumor and Tissue Bank of the Department of Neurosurgery, University of Debrecen, were studied using the methods of molecular biology. mRNA and protein expression were measured in 20 ECM components, which were chosen after a thorough study of the literature. ${ }^{11,13,14,16,22-25}$ Cell surface receptors, their extracellular matrix ligands, fibrous components, glycoproteins and 
enzymes of the ECM were included in this study because members of these groups are all important in the process of glioma invasion. There are more than hundreds of relevant molecules, but based on our previous reports, twenty of them were selected for the recent investigations. ${ }^{9,10,12,26-28}$ Table 1 shows the molecules involved in the study.

\section{Patients and tissue samples}

Flash frozen GBM samples of 26 patients from the Brain Tumor and Tissue Bank of our departments were chosen for examination. The mean age of patients was $58.69 \pm 8.01$ (minimum: 43 years, maximum: 75 years). Each patient received the same treatment protocol: subtotal tumor resection followed by concurring chemo-irradiation and temozolomide monotherapy according to the Stupp protocol. In case of recurrence while on temozolomide monotherapy, bevacizumab monotherapy was initiated and continued as long as the tumor progressed further or the patients' clinical condition allowed. Samples were divided into two groups based on the median overall survival of patients, and 23 months was determined as a separating parameter, as suggested by the literature and the author's institutional statistics (median overall survival for glioblastoma patients receiving the Stupp protocol complemented with bevacizumab). Patients with an OS of 23 months or less are included in Group A ( $n=12)$, and patients whose OS is more than 23 months ( $n=14)$ are included in Group B. The chosen samples were then analyzed to measure the mRNA and protein levels of the molecules. Table 2 presents the summary of the clinical data of patients included in the study.

\section{Immunohistochemistry}

Samples were analyzed to determine prognostic factors isocitrate dehydrogenase-1 (IDH1) and Ki-67 protein expression with fluorescent labeling. $4 \mu \mathrm{m}$ thick sections from formalinfixed, paraffin-embedded blocks have been stained for the R132H mutant specific IDH1 
mouse monoclonal antibody (DIA H09) (Dianova, Germany) and Ki-67/MIB-1 mouse

monoclonal antibody (M7240) (DAKO, Denmark) according to the manufacturer's

instructions, using a 1:50 and 1:200 dilution for IDH1 and Ki-67, respectively.

\section{mRNA Expression Measurements}

The mRNA expression level of 20 molecules was determined through real-time quantitative reverse transcriptase-polymerase chain reaction (QRT-PCR) as described previously ${ }^{9,28}$. Freshly frozen tissue samples were first pulverized and then homogenized using TriReagent ${ }^{\circledR}$ (Invitrogen, USA). Total RNA was isolated from TriReagent lysates according to the manufacturer's instructions. A NanoDrop ${ }^{\circledR}$ ND-1000 Spectrophotometer (NanoDrop Technologies, USA) was used to measure the quantity and purity of RNA. In the next step, reverse transcription was performed to convert total RNA to single-stranded cDNA with the help of a High-Capacity cDNA Archive Kit with RNasin (Applied Biosystems, USA). The cDNA was then loaded onto a microfluidic card (cDNA from $100 \mathrm{ng}$ of total RNA per port). An Applied Biosystems 7900HT real-time PCR system with Micro Fluidic Card upgrade (Applied Biosystems, USA) was used to perform TaqMan low-density array (TLDA) experiments. The Micro Fluidic Cards were analyzed with SDS 2.1 software as relative quantification studies, and the $\mathrm{Ct}$ (Cycle threshold) values were exported for further analysis. $\beta$-actin and glyceraldehyde 3-phosphate dehydrogenase housekeeping genes exhibited the least variation among the samples and were used as reference genes to calculate the $\mathrm{dCt}$ value for each gene. Expression values were calculated using the comparative CT method, as described previously ${ }^{29}$. After determining the mRNA levels, concentrations of the transcribed proteins were measured with a mass spectrometer to discover the expressional changes. 
Virga et al.

\section{Protein Expression Measurements}

After determining the mRNA levels, concentrations of the transcribed proteins were measured with a mass spectrometer to uncover expressional changes as described previously ${ }^{9,28}$. Proteomic measurements were reproducibly acceptable in 14 cases. Tissue homogenization for protein analysis was performed as described in the case of RNA purification. However, a lysis buffer containing 50 mM Tris, 1 mM EDTA, 17 mM betamercaptoethanol, and $0.5 \%$ Triton- $\mathrm{X} 100^{\mathrm{TM}}$ was used in this case for tissue lysis. The protein content was measured using the Bradford method, and equal amounts of proteins were used for in-solution trypsin digestion ${ }^{30}$. The selected reaction monitoring (SRM)-based targeted proteomic method was developed for relative protein amount determination ${ }^{31-34}$. For protein concentration estimation, the area under the curve of the acquired spectra was calculated, and the SRM spectra were used for AUC calculations in which the intensity of the signal exceeds $500 \mathrm{cps}$. Data integration was conducted with the help of the Analyst 1.4.2 software based on the curve shape determined from pilot analyses.

\section{Statistical analysis}

Survival and expression data were statistically analyzed with independent samples t-test, chi-square test, and comparison of ratios. To determine the effect of certain molecule patterns on survival, we used locally weighted learning and J48 pruned tree statistical classifiers. Statistical analysis was conducted by a biomathematician using the Weka 3.6 statistical program.

\section{RESULTS}

\section{Clinical parameters of patients do not influence patient survival significantly}

The mean progression free survival (PFS) of patients was $8.0 \pm 7.01$ months for Group A and 14.4 \pm 8.3 for Group B. The mean OS was $13.4 \pm 8.3$ months and 35.2 \pm 13.6 months for Group A 
and Group B, respectively. The PFS and OS significantly differed between the two groups (PFS: $p=0.04$, OS: $p<0.001$ ). The mean age of patients in Group A was $61.3 \pm 5.88$ years and that for Group B was $56.42 \pm 9.06$ years $(p=0.12)$. The homogeneity of groups was not different in terms of lateralization or lobular location of the tumors $(p=0.92$ and $p=0.52$, respectively). The average tumor size was $49.3 \pm 20.8 \mathrm{~mm}$ in Group A and $43.53 \pm 17.7 \mathrm{~mm}$ in Group B; the groups did not differ from one another significantly $(p=0.42)$. The rate of reoperations due to recurrence was also statistically indifferent between Group A and B ( $7 / 12$ vs. $12 / 14, p=0.13)$. These findings indicate that patients in Group A and Group B do not diverge significantly from one another except in the PFS and OS data.

\section{Ki-67 and IDH-1 revealed no heterogeneity between the samples of patients with different prognosis}

IHC analysis of the samples for known prognostic marker IDH-1 revealed that $25 \%$ and $28.5 \%$ of the samples were IDH-1 positive in group A and group B, respectively. The proportion of IDH-1 positive samples did not differ significantly in the two groups with different survival. Ki-67/MIB1 labeling index (LI) was also determined. Average LI was $12.5 \pm 6.09$ for group A and $18.61 \pm 15.11$ for group $B$; the alteration is not statistically different.

\section{Various survival groups have different mRNA expression patterns of invasion-related molecules}

After analyzing the individual mRNA levels of the measured molecules, no significant differences were found between the two groups. The difference in the amount of mRNA might not be significant, but it was certainly present as some components were expressed to a higher degree in the patient group with better prognosis, while others were present in a smaller amount (Figure 1). These differences have a small effect alone, but when they are jointly analyzed, their individual insignificant relevancies add up. 
The expression of 20 invasion-related molecules was examined at the same time. The expression pattern of the two prognostic groups was created and used for studying the effect of invasion-related molecules on patient outcome. Patients of various survival groups were separable using the expression pattern by statistical classifier algorithm called J48 pruned tree (see Table 3), thus proving the specific and significant role of the expression pattern of glioblastoma samples in the prognosis of the disease. The method identified $84.6 \%$ of the patients' prognosis correctly, the sensitivity of the test was 0.852 , and its positive predictive value was 0.858 . The statistical analysis also revealed the prominent role of certain ECM components. The differences in the expression level of these molecules were substantial to distinguish separate prognostic groups. The mRNA level of brevican and integrin beta 1 proved to be important in the differentiation between Group A and Group B, as the decision tree used expression levels of these molecules to determine the prognosis (i.e. group A or group B) of the patients. Both molecules are equally important, however the first decision is based upon the integrin beta 1 levels, and the second decision is based upon brevican expression.

\section{Protein expression analysis confirms the connection of the expression pattern of invasion- related ECM components with patient outcome while highlighting more key molecules in glioma invasion}

In the analysis of proteomic measurements, no significant difference in the amount of individual proteins could be confirmed. Nonetheless, differences in the average level of ECM components playing a role in tumor invasion were registered, thus further suggesting the importance of the expression pattern of gliomas (Figure 2). The expression spectrum created from the protein levels of ECM components could be used for the assessment of patient outcome, as $85.7 \%$ of the patients' prognosis was correctly identified (sensitivity: 0.857 , 
Virga et al.

positive predictive value: 0.893$)$. Note that all of the patients with better outcome were correctly identified (100\%, Table 4). The protein levels of some molecules seemed to be more important in the patient differentiating process. These ECM components could play an important role in the invasivity of glioblastoma cells, and therefore the protein amounts of these molecules could influence patient survival more than other molecules. Brevican, cadherin-12, integrin alpha-3, as well as laminin alpha-4 and beta-1 proteins were identified statistically as key molecules by the decision making algorithm called locally weighted learning (LWL). LWL uses the expression levels of the mentioned proteins as equally evaluated attributes when deciding if a sample belongs to group A or group B. This means that all the five protein levels are needed at the same time to determine the prognostic group.

\section{DISCUSSION}

GBM is the most common malignant disease of the central nervous system ${ }^{1,2}$. The prognosis is modest despite novel treatment strategies. The poor patient outcome is mostly attributed to the extensive peritumoral infiltration of tumor cells ${ }^{12,14,16,17,24,27}$. Interaction among glioma cells and ECM components of the neighboring brain and the changed micro-milieu caused by the modified composition of ECM are important factors in tumor invasion 13,22,24,35. Clinicians treating glioma patients should be able to assess prognosis and survival. Molecular prognostic markers (e.g., MGMT methylation, 1p19q co-deletion, IDH1 mutation, etc.) today have no influence on routinely used treatment protocols in glioblastoma patients $5,19,21,36$. Therefore, a demand exists for a relatively simple, widely available, and potentially routinely performable method to analyze glioblastoma samples and asses prognosis. As curative total surgical removal is impossible because of peritumoral infiltration that leads to 
inevitable local recurrences, examining invasion-related molecules has been the focus of interest recently. Our research aims to study the correlation between ECM components playing a role in tumor invasion and GBM patient survival. To study the expression of these molecules, the mRNA and protein expressions of 20 ECM components in samples from glioblastoma patients were determined.

Regarding OS, two groups of glioblastoma patients were created. Group A consisted of 12 patients, with mean PFS: $8.0 \pm 7.01$ months and OS: $13.4 \pm 8.3$ months. Group B consisted of 14 patients, with mean PFS: $14.42 \pm 8.3$ months and OS: $35.2 \pm 13.6$ months. The expression levels of the invasion-related ECM molecules create a characteristic invasion spectrum for each group. Through statistical analysis, the invasion spectrum was proved to be specific for the selected groups, and it was useful to separate patients with poor and better prognosis. Furthermore, studying the expression pattern of ECM components highlights the significance of certain molecules in prognosis; therefore, the invasion spectrum helps to identify potential therapeutic targets. Brevican, cadherin-12, integrin beta-1 and alpha-3, as well as laminin alpha-4 and beta-1 were selected as key molecules by statistical classifiers LWL and J48 pruned tree. Previous studies have described an increased amount of brevican RNA in glioma cells with increased motility ${ }^{37,26}$. In Group A, the group with poor prognosis, the mRNA levels of brevican was increased compared with Group B. Therefore, the increased expression of brevican correlates with a more invasive phenotype of glioblastoma. Cadherin12 certainly has a role in other types of cancer, such as colorectal cancer, and its role was previously described in glioblastoma in rat models ${ }^{23,38,39}$. Cadherin-12 expression has been reported to be inversely proportional to tumor invasivity. Our research confirms these data, as the levels of cadherin-12 mRNA were higher in Group B than in Group A. As described in 
Virga et al.

the literature, the level of integrin beta- 1 increases in tumors, especially in the perivascular areas and on the infiltrating surface of tumor masses ${ }^{25,35,40,41}$. GBM is known to be highly hypervascularized, and increased vascularization is an important criterion in histopathological diagnosis (astrocytoma WHO grade IV). The decreased level of integrin beta-1 detected in a recent study in Group B with better prognosis suggests less intensive neovascularization, and a decreased degree of infiltration was present in those samples. As integrin alpha-3 is a frequent heterodimer partner of integrin beta-1, it is not surprising to have it identified as an important factor in glioma invasiveness ${ }^{25,35,42}$. Better prognosis correlates with decreased amount of integrin alpha-3. Laminin apha- 4 and beta- 1 protein levels are important factors according our findings. The laminin beta-1 chain is a unit of many laminin isoforms (laminin-1, $-2,-6,-8,-10,-12$ ), while the alpha-4 chain is a component of two isoforms (laminin-8 and -9) ${ }^{43,44}$. Previously, these laminin chains were found to be secreted by glioma cells, and their role in peritumoral infiltration was found to be in the adhesion of cancer cells to ECM components and in cellular migration ${ }^{43-46}$. More importantly, laminin-1, -8 and -10 are receptors for integrin apha- 3 beta-1, which is responsible for the increased motility of glioma cells. Therefore our results confirm themselves. Like those of integrins, levels of laminin alpha- 4 and beta- 1 decreased in Group B compared with Group A. Therefore, the low levels of alpha-4 and beta-1 laminins are associated with less invasive tumor phenotype and better prognosis.

Both RNA and protein expression studies are suitable to estimate prognosis. The expression pattern of the ECM components provides a specific invasion spectrum of the samples that can be used to efficiently appraise patients' survival. From a clinical point of view, the method has a high positive predictive value, especially in group with worse prognosis. 
Receiver operation characteristic (ROC) analysis, which estimates the accuracy of clinical tests, revealed that the method separates patients with poor from those with better prognosis well. The area under curve was 0.775 for the ROC curve of the invasion spectrum created from mRNA levels and 0.875 for the ROC curve of proteomic studies. These values, especially in case of a protein invasion spectrum, confirm the reliability of our method.

\section{CONCLUSIONS}

In the examination of tumor samples taken from glioblastoma patients, a single molecule was found to have no significant influence on patients' survival. A specific invasion spectrum can be determined by measuring the expression of a selected panel of invasion-related molecules. The study of the expression pattern of invasion-related molecules confirms the connection between patient survival and invasion spectrum, which can be used as a prognostic factor. The method that evaluates the expression of multiple molecules jointly is reliable, and the true positive rate (sensitivity) can be further improved with the addition of properly chosen molecules.

The analysis of the invasion spectrum of glioblastoma samples further presses the need for the complementation of the current treatment protocols. Additionally, the study on the invasion spectrum reveals information on the importance of certain ECM components. This information can guide scientists in choosing the targets for molecular anti-invasive research and can aid neuro-oncologists when making personalized treatment plans in the future.

\section{ACKNOWLEDGEMENTS}

This study was supported by Hungarian Brain Research Program - Grant No. KTIA_13_NAPA-V/3, II/7. and A. Klekner by the János Bolyai Scholarship of the Hungarian Academy of Sciences. 
Virga et al.

(1)

2

5

6

7

8

9

10

11

12

13

14

15

16

17

18

19

20

21

22

23

24

25

26

27

28

29

30

31

32

33

34

35

36

37

38

39

40

41

42

43

44

45

46

47

48

49

50

51

52

53

54

55

56

57

58

59

60 


\section{REFERENCES}

1. Ostrom QT, Gittleman H, Liao P, et al. CBTRUS Statistical Report: Primary Brain and Central Nervous System Tumors Diagnosed in the United States in 2007-2011. NeuroOncology . 2014;16 (suppl 4 ):iv1-iv63. doi:10.1093/neuonc/nou223.

2. Urbańska K, Sokołowska J, Szmidt M, et al. Glioblastoma multiforme - an overview. Contemp Oncol. 2014;18(5):307-312. doi:10.5114/wo.2014.40559.

3. Helseth R, Helseth E, Johannesen TB, et al. Overall survival, prognostic factors, and repeated surgery in a consecutive series of 516 patients with glioblastoma multiforme. Acta Neurol Scand. 2010;122(3):159-167. doi:10.1111/j.16000404.2010.01350.x.

4. Johnson DR, O'Neill BP. Glioblastoma survival in the United States before and during the temozolomide era. J Neurooncol. 2012;107(2):359-364. doi:10.1007/s11060-0110749-4.

5. Bralten LBC, French PJ. Genetic alterations in Glioma. Cancers (Basel). 2011;3(1):11291140. doi:10.3390/cancers3011129.

6. Johnson DR, Galanis E. Medical management of high-grade astrocytoma: current and emerging therapies. Semin Oncol. 2014;41(4):511-522.

doi:10.1053/j.seminoncol.2014.06.010.

7. Stupp R, Mason WP, van den Bent MJ, et al. Radiotherapy plus concomitant and adjuvant temozolomide for glioblastoma. N Engl J Med. 2005;352(10):987-996. doi:10.1056/NEJMoa043330.

8. Chamberlain MC. Bevacizumab for the treatment of recurrent glioblastoma. Clin Med Insights Oncol. 2011;5:117-129. doi:10.4137/CMO.S7232.

9. Petrás M, Hutóczki G, Varga I, et al. Expression pattern of invasion-related molecules in cerebral tumors of different origin. Magy Onkológia. 2009;53(3):253-258. doi:10.1556/MOnkol.53.2009.3.3.

10. Klekner A, Varga I, Bognár L, et al. Extracellular matrix of cerebral tumors with different invasiveness. Ideggyogy Sz. 2010;63(1-2):38-43.

11. Nicholson C, Syková E. Extracellular space structure revealed by diffusion analysis. Trends Neurosci. 1998;21(5):207-215. doi:10.1016/S0166-2236(98)01261-2.

12. Klekner A, Virga J, Toth J, et al. [The role of extracellular matrix components in the invasion of intracranial malignancies]. Magy Onkol. 2013;57(4):222-231. doi:MagyOnkol.2013.57.4.222.

13. Bellail AC, Hunter SB, Brat DJ, et al. Microregional extracellular matrix heterogeneity in brain modulates glioma cell invasion. Int J Biochem Cell Biol. 2004;36(6):1046-1069. doi:10.1016/j.biocel.2004.01.013.

14. Gladson CL. The extracellular matrix of gliomas: modulation of cell function. J Neuropathol Exp Neurol. 1999;58(10):1029-1040.

15. Klekner Á, Hutóczki G, Virga J, et al. Expression pattern of invasion-related molecules 
in the peritumoral brain. Clin Neurol Neurosurg. 2015;139:138-143. doi:10.1016/j.clineuro.2015.09.017.

16. Rubenstein BM, Kaufman LJ. The role of extracellular matrix in glioma invasion: a cellular Potts model approach. Biophys J. 2008;95(12):5661-5680. doi:10.1529/biophysj.108.140624.

17. Chintala SK, Rao JK. Invasion of human glioma: role of extracellular matrix proteins. Front Biosci. 1996;1:d324-d339.

18. Kesanakurti D, Chetty C, Dinh DH, Gujrati M, Rao JS. Role of MMP-2 in the regulation of IL-6/Stat3 survival signaling via interaction with $\alpha 5 \beta 1$ integrin in glioma. Oncogene. 2013;32(3):327-340. doi:10.1038/onc.2012.52.

19. Hegi ME, Diserens A-C, Gorlia T, et al. MGMT gene silencing and benefit from temozolomide in glioblastoma. N Engl J Med. 2005;352(10):997-1003. doi:10.1056/NEJMoa043331.

20. Krex D, Klink B, Hartmann C, et al. Long-term survival with glioblastoma multiforme. Brain. 2007;130(Pt 10):2596-2606. doi:10.1093/brain/awm204.

21. Stupp R, Hegi ME, Mason WP, et al. Effects of radiotherapy with concomitant and adjuvant temozolomide versus radiotherapy alone on survival in glioblastoma in a randomised phase III study: 5-year analysis of the EORTC-NCIC trial. Lancet Oncol. 2009;10(5):459-466. doi:10.1016/S1470-2045(09)70025-7.

22. Gingras $M$, Roussel $E$, Bruner JM, et al. Comparison of cell adhesion molecule expression between glioblastoma multiforme and autologous normal brain tissue. $J$ Neuroimmunol. 1995;57(1-2):143-153. doi:10.1016/0165-5728(94)00178-Q.

23. Zhao J, Li P, Feng $\mathrm{H}$, et al. Cadherin-12 contributes to tumorigenicity in colorectal cancer by promoting migration, invasion, adhersion and angiogenesis. $J$ Trans/ Med. 2013;11:288.

http://www.pubmedcentral.nih.gov/articlerender.fcgi?artid=3879717\&tool=pmcentr ez\&rendertype $=$ abstract.

24. Tysnes BB, Mahesparan R. Biological mechanisms of glioma invasion and potential therapeutic targets. J Neurooncol. 2001;53(2):129-147.

25. Knott JCA, Mahesparan R, Garcia-Cabrera I, et al. Stimulation of extracellular matrix components in the normal brain by invading glioma cells. Int J Cancer. 1998;75(6):864872.

26. Varga I, Hutóczki G, Szemcsák CD, et al. Brevican, neurocan, tenascin-C and versican are mainly responsible for the invasiveness of low-grade astrocytoma. Pathol Oncol Res. 2012;18(2):413-420.

27. Klekner A, Hutoczki G, Virga J, et al. Expression pattern of invasion-related molecules in the peritumoral brain. Clin Neurol Neurosurg. 2015;139:138-143. doi:10.1016/j.clineuro.2015.09.017.

28. Varga I, Hutóczki G, Petrás M, et al. Expression of invasion-related extracellular matrix molecules in human glioblastoma versus intracerebral lung adenocarcinoma metastasis. Zentralb/ Neurochir. 2010;71(4):173-180. 
29. Livak KJ, Schmittgen TD. Analysis of relative gene expression data using real-time quantitative PCR and the 2(-Delta Delta C(T)) Method. Methods. 2001;25(4):402-408.

30. Bradford M. Rapid and Sensitive Method for Quantification of Microgram Quantities of Protein utilizing principle of Protein-Dye-Binding. Anal Biochem. 1976;72(1-2):248254.

31. James A, Jorgensen C. Basic design of MRM assays for peptide quantification. Methods Mol Biol. 2010;658:167-185.

32. luga $C$, Seicean A, lancu $C$, et al. Proteomic identification of potential prognostic biomarkers in resectable pancreatic ductal adenocarcinoma. Proteomics. 2014;14(78):945-955.

33. Qian W-J, Jacobs JM, Liu T, et al. Advances and challenges in liquid chromatographymass spectrometry-based proteomics profiling for clinical applications. Mol Cell Proteomics. 2006;5(10):1727-1744.

34. Lange $V$, Picotti $P$, Domon $B$, et al. Selected reaction monitoring for quantitative proteomics: a tutorial. Mol Syst Biol. 2008;4:222.

35. Mahesparan R, Read T-A, Lund-Johansen M, et al. Expression of extracellular matrix components in a highly infiltrative in vivo glioma model. Acta Neuropathol.

2003;105(1):49-57.

36. Goodenberger ML, Jenkins RB. Genetics of adult glioma. Cancer Genet. 2012;205(12):613-621. doi:10.1016/j.cancergen.2012.10.009.

37. Gary SC, Kelly GM, Hockfield S. BEHAB/brevican: a brain-specific lectican implicated in gliomas and glial cell motility. Curr Opin Neurobiol. 1998;8(5):576-581. doi:10.1016/S0959-4388(98)80083-4.

38. Asano K, Duntsch CD, Zhou Q, et al. Correlation of N-cadherin expression in high grade gliomas with tissue invasion. J Neurooncol. 2004;70:3-15. doi:10.1023/B:NEON.0000040811.14908.f2.

39. Maret D, Gruzglin E, Seyed Sadr M, et al. Surface Expression of Precursor N-cadherin Promotes Tumor Cell Invasion. Neoplasia. 2010;12(12):1066-IN38.

doi:10.1593/neo.10954.

40. D’Abaco GM, Kaye AH. Integrins: molecular determinants of glioma invasion. J Clin Neurosci. 2007;14(11):1041-1048. doi:10.1016/j.jocn.2007.06.019.

41. Färber K, Synowitz M, Zahn G, et al. An alpha5beta1 integrin inhibitor attenuates glioma growth. Mol Cell Neurosci. 2008;39(4):579-585.

doi:10.1016/j.mcn.2008.08.005.

42. Fukushima $\mathrm{Y}$, Ohnishi T, Arita N, et al. Integrin alpha3beta1-mediated interaction with laminin-5 stimulates adhesion, migration and invasion of malignant glioma cells. Int J Cancer. 1998;76(1):63-72. doi:10.1002/(SICI)1097-0215(19980330)76:1<63::AIDIJC11>3.0.CO;2-H.

43. Patarroyo $M$, Tryggvason $\mathrm{K}$, Virtanen I. Laminin isoforms in tumor invasion, angiogenesis and metastasis. Semin Cancer Biol. 2002;12(3):197-207. 
Virga et al.

doi:10.1016/S1044-579X(02)00023-8.

44. Kawataki $\mathrm{T}$, Yamane $\mathrm{T}$, Naganuma $\mathrm{H}$, et al. Laminin isoforms and their integrin receptors in glioma cell migration and invasiveness: Evidence for a role of alpha5laminin(s) and alpha3beta1 integrin. Exp Cell Res. 2007;313(18):3819-3831. doi:10.1016/j.yexcr.2007.07.038.

45. Nagato $\mathrm{S}, \mathrm{Nakagawa} \mathrm{K}$, Harada $\mathrm{H}$, et al. Downregulation of laminin alpha4 chain expression inhibits glioma invasion in vitro and in vivo. Int J Cancer. 2005;117(1):4150. doi:10.1002/ijc.21102.

46. Ljubimova JY, Lakhter AJ, Loksh A, et al. Overexpression of $\alpha 4$ chain-containing laminins in human glial tumors identified by gene microarray analysis. Cancer Res. 2001;61(14):5601-5610. http://www.scopus.com/inward/record.url?eid=2-s2.00035878071\&partnerID=tZOtx3y1. 
Virga et al.

\section{FIGURE CAPTIONS}

Figure 1. mRNA expression differences between Group A and Group B among invasionrelated molecules. The bars represent the ratio of $m R N A$ levels of the given molecule in the two survival groups. Bars below 0 show that the level of the given molecule decreased in Group B compared with Group A. Expression data are represented by the natural logarithm of the measured level of the given molecule. Group $A=$ patients with an OS $\leq 23$ months, Group $B=$ with an OS $>23$ months

Figure 2. Protein expressional differences between Group A and B among invasion-related molecules. The bars represent the ratio of $m R N A$ levels of the given molecule in the two prognostic groups. Bars below 0 show that the level of the given molecule in Group $B$ is below that of Group $A$ and vice versa. Group $A=$ patients with an $O S \leq 23$ months, Group $B=$ with an $O S>23$ months 
Virga et al.

\section{TABLE LEGENDS}

Table 1. ECM components selected for the study. The expression level of these molecules was determined by QRT-PCR for the mRNA levels and mass spectroscopy for the protein levels.

Table 2. Summarized clinical data of the two groups of patients with different survival rates. Mean age of patients was set at the time of diagnosis. Tumor size was measured as the longest diameter of the tumor mass. Postoperative Karnofsky Performance Score (KPS) was set by experienced clinicians, progression free survival (PFS) was calculated from the date of the first operation and the date of first progression/recurrence confirmed by MRI. (OS = overall survival, $R=$ right side, front $=$ frontal, temp=temporal, pariet=parietal, occipit=occipital, cerebell=cerebellar, multilob=multilobular, postop. = postoperative, reop = re-operated)

Table 3. Separation of groups after the statistical analysis of the mRNA expression data of invasion-related molecules. (No. = number, ROC = receiver operation characteristic)

Table 4. Separation of groups after the statistical analysis of the protein expression data of invasion-related molecules. (No. = number, $\mathrm{ROC}=$ receiver operation characteristic). Group $A=$ patients with an OS $\leq 23$ months, Group $B=$ with an OS $>23$ months 
Figure 1. mRNA expression differences between Group A and Group B among invasion-related molecules. The bars represent the ratio of mRNA levels of the given molecule in the two survival groups. Bars below 0 show that the level of the given molecule decreased in Group B compared with Group A. Expression data are represented by the natural logarithm of the measured level of the given molecule. Group $A=$ patients with an OS $\leq 23$ months, Group B = with an OS $>23$ months $160 \times 109 \mathrm{~mm}$ (96 x 96 DPI) 
Figure 2. Protein expressional differences between Group A and B among invasion-related molecules. The bars represent the ratio of mRNA levels of the given molecule in the two prognostic groups. Bars below 0 show that the level of the given molecule in Group $B$ is below that of Group $A$ and vice versa. Group $A=$ patients with an OS $\leq 23$ months, Group B = with an OS > 23 months 


\begin{tabular}{|c|c|}
\hline 1 & EGFR (ErbB1) \\
\hline 2 & ERBB2 \\
\hline 3 & HMMR (CD168, RHAMM) \\
\hline 4 & integrin, alpha-1 chain \\
\hline 5 & integrin, alpha-3 chain \\
\hline 6 & integrin, alpha-7 chain \\
\hline 7 & integrin, beta-1 chain \\
\hline 8 & laminin, alpha-4 chain \\
\hline 9 & laminin, beta- 1 chain \\
\hline 10 & MMP-2 \\
\hline 11 & MMP-9 \\
\hline 12 & brevican \\
\hline 13 & cadherin-12 \\
\hline 14 & collagen, type III, alpha- 1 chain \\
\hline 15 & fibronektin-1 \\
\hline 16 & neurocan \\
\hline 17 & syndecan-1 \\
\hline 18 & tenascin-C \\
\hline 19 & tenascin- $R$ \\
\hline 20 & versican \\
\hline
\end{tabular}




\begin{tabular}{|c|cccccccc|}
\hline & $\begin{array}{c}\text { Mean } \\
\text { age of } \\
\text { patients } \\
\text { (years) }\end{array}$ & $\begin{array}{c}\text { Mean } \\
\text { tumor } \\
\text { size } \\
\text { (mm) }\end{array}$ & $\begin{array}{c}\text { Mean } \\
\text { postop. } \\
\text { KPS }\end{array}$ & $\begin{array}{c}\text { Mean } \\
\text { PFS } \\
\text { (months) }\end{array}$ & $\begin{array}{c}\text { Mean } \\
\text { OS } \\
\text { (month) }\end{array}$ & $\begin{array}{c}\text { Tumor } \\
\text { side } \\
\text { (\%) }\end{array}$ & $\begin{array}{c}\text { Location } \\
\text { (\%) }\end{array}$ & $\begin{array}{c}\text { Reop. } \\
\text { patients } \\
\text { (\%) }\end{array}$ \\
\hline & & & & & & & Front: 25 & Temp: 25 \\
Group A \\
(n=12)
\end{tabular}




\begin{tabular}{|c|c|c|c|c|c|}
\hline & $\begin{array}{c}\text { Correctly } \\
\text { No. }\end{array}$ & $\begin{array}{c}\text { ied cases } \\
\%\end{array}$ & Sensitivity & ROC value & $\begin{array}{c}\text { Positive } \\
\text { predictive } \\
\text { value }\end{array}$ \\
\hline Group A & $9 / 12$ & $75.0 \%$ & 0.75 & 0.775 & 0.90 \\
\hline Group B & $13 / 14$ & $92.8 \%$ & 0.92 & 0.775 & 0.82 \\
\hline Total/Weighted average & $22 / 26$ & $84.6 \%$ & 0.84 & 0.775 & 0.85 \\
\hline
\end{tabular}




\begin{tabular}{|l|c|c|c|c|c|}
\hline & \multicolumn{2}{|c|}{$\begin{array}{c}\text { Correctly identified cases } \\
\text { No. }\end{array}$} & Sensitivity & ROC value & $\begin{array}{c}\text { Positive } \\
\text { predictive } \\
\text { value }\end{array}$ \\
\hline Group A & $6 / 8$ & $0.75 \%$ & 0.75 & 0.875 & 1 \\
\hline Group B & $6 / 6$ & $100 \%$ & 1 & 0.875 & 0.75 \\
\hline Total/Weighted average & $12 / 14$ & $85.7 \%$ & 0.857 & 0.875 & 0.893 \\
\hline
\end{tabular}

